\title{
Perbandingan Sistem Proteksi Generator SWD Dengan Generator Mitsubishi Di Unit PLTD Tello
}

\author{
Kurniawati Naim 1 \\ ${ }^{1}$ Jurusan Elektro Politeknik Negeri Ujung Pandang \\ email: nianaim09@poliupg.ac.id
}

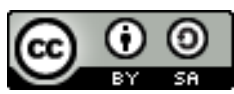

\begin{abstract}
Abstrak
Sistem proteksi banyak digunakan pada perangkat-perangkat kelistrikan. Sistem proteksi diharapkan dapat menjaga perangkat-perangkat dari gangguan-gangguan yang dapat mengakibatkan kesalahan kerja maupun kerusakan. PLTD Tello smenggunakan generator SWD dan generator Mitsubishi. Penelitian ini bertujuan untuk menganalisis spesifikasi rele proteksi yang digunakan pada generator SWD dan generator Mitsubishi di Unit PLTD Tello, menganalisis jenis gangguan yang sering terjadi pada sistem proteksi generator SWD dan generator Mitsubishi di PLTD Tello dan menganalisis perbandingan yang ada pada sistem proteksi generator SWD dengan generator Mitsubishi di Unit PLTD Tello. Metode penelitian yang dilakukan yaitu Data yang diperoleh akan diolah dan dianalisis. Adapun nilai yang didapatkan selama penelitian akan diolah secara matematis sesuai standar yang diperoleh dari rekomendasi sistem proteksi yang dikeluarkan oleh PT. PLN (Persero) PLTD Tello dan berlaku untuk waktu tersebut. Relay proteksi generator SWD PLTD Tello PT.PLN (Persero) terdiri dari 7 proteksi.Sedangkan pada Relay proteksi generator Mitsubishi PLTD Tello PT. PLN (Persero) terdiri dari 12 proteksi. Pada tahun 2015, terjadi gangguan pada generator Mitsubishi yang menyebabkan differensial relay bekerja. Pada tahun 2016, terjadi gangguan pada Generator SWD yang menyebabkan over voltage relay bekerja.
\end{abstract}

Kata Kunci: generator SWD, generator Mitsubishi, proteksi

\section{PENDAHULUAN}

Sistem proteksi merupakan suatu susunan perangkat proteksi secara lengkap yang terdiri dari perangkat utama dan perangkat-perangkat lain yang dibutuhkan untuk melakukan fungsi tertentu berdasarkan prinsip-prinsip proteksi. Sistem proteksi diharapkan dapat menjaga perangkat-perangkat dari gangguan-gangguan yang dapat mengakibatkan kesalahan kerja maupun kerusakan.

Salah satu alat kelistrikan yang membutuhkan sistem proteksi yaitu generator. Generator merupakan komponen utama pada pembangkit untuk bisa menghasilkan energi listrik. Ada berbagai jenis generator berdasarkan merek atau perusahaan pembuatnya. Pada pembangkit listrik generator yang digunakan tidak hanya satu dan tidak pula terikat pada satu jenis merk generator saja. generator yang digunakan harus memiliki spesifikasi yang bagus agar dapat bekerja secara optimal dan maksimal. Generator yang baik harus memiliki sistem proteksi yang baik pula. Karakteristik sistem proteksi juga perlu diperhatikan sebagai kriteria-kriteria baik tidaknya sebuah sistem proteksi. Karakteristik yang baik pada sistem proteksi diharapkan mampu mengatasi keadaan abnormal yang terjadi pada suatu sistem proteksi karena gangguan-gangguan yang sering terjadi pada generator dapat menjadi batu sandungan dalam proses pembangkitan energi listrik. Selain berdampak bagi masyarakat luas juga memberikan kerugian tersendiri bagi perusahaan pembangkit karena kerusakan yang terjadi pada generator.

PLTD Tello merupakan salah satu tempat pembangkitan energi listrik dengan memanfaatkan sumber energi solar. Di PLTD Tello sebelum menggunakan generator SWD telah lebih dahulu menggunakan generator Mitsubishi. Kedua generator ini digunakan dalam menghasilkan energi listrik yang kemudian disalurkan ke gardu induk.

Penelitian-penelitian yang ada sebelumnya hanya membahas mengenai sistem proteksi generator pada umumnya. Pada kesempatan ini, penulis mengkhususkan penelitian pada perbandingan sistem proteksi pada generator SWD dan Mistsubshi untuk mengetahui bagaimana sistem proteksi yang diterapkan pada generator SWD Dan Mitsubishi. Selain itu pula, perlu diketahui kekurangan dari kedua generator tersebut beserta gangguan-gangguan yang sering terjadi selama 2 tahun terakhir masa operasi generator tersebut.

Adapun tujuan penelitian ini yaitu Menguraikan spesifikasi rele proteksi yang digunakan pada generator SWD dan generator 
Mitsubishi di Unit PLTD Tello, Menguraikan jenis gangguan yang sering terjadi pada sistem proteksi generator SWD dan generator Mitsubishi di PLTD Tello dan menganalisis perbandingan yang ada pada sistem proteksi generator SWD dengan generator Mitsubishi di Unit PLTD Tello.

Uraian tentang pentingnya sistem proteksi beserta karakteristiknya terhadap gangguan pada generator di PLTD Tello menjadi dasar penulis untuk melakukan penelitian di PLTD Tello dengan judul, "Perbandingan Sistem Proteksi Pada Generator SWD Dan Generator Mitsubishi di Unit PLTD Tello".

\section{KAJIAN LITERATUR}

\section{Konsep Dasar Generator}

Generator merupakan komponen paling utama dalam proses pembangkitan energi listrik. Generator digunakan oleh semua perusahaan pembangkit dalam menghasilkan energi listrik. Generator dari segi fungsi yaitu mengkonversi energi mekanik menjadi energi listrik. Dari pengertian, terlihat jelas betapa pentingnya generator dalam sistem tenaga listrik. Oleh sebab itu, generator perlu mendapatkan perlindungan dan pemeliharaan yang baik selama pengoperasiannya agar generator tidak mengalami kerusakaan atau gangguan terhadap fungsi kerjanya sehingga dapat terus menghasilkan energi listrik sesuai kebutuhan manusia. [1]

Prinsip yang digunakan oleh generator adalah [1]

a. Bila hanya sebuah konduktor saja yang diputar dalam sebuah medan magnet, maka gaya listrik yang dihasilkan juga sedikit.

b. Bila konduktor yang digunakan semakin banyak maka akan dihasilkan gaya listrik semakin besar. Demikian pula bila konduktor diputar semakin cepat di dalam medan magnet, maka bertambah besar pula gaya listriknya.

c. Bila konduktor yang berbentuk coil (kumparan), maka jumlah gaya listrik yang terjadi semakin besar.

Generator dibedakan menjadi dua yaitu [1]

a. Generator DC. Generator menghasilkan gaya gerak listrik induksi searah sehingga disebut generator arus searah.

b. Generator AC. Generator ini menghasilkan gaya gerak listrik induksi bolak-balik sehingga disebut generator arus bolak-balik. Generator inilah yang digunakan oleh PLN untuk menghasilkan listrik.

\section{Gangguan pada Generator}

Gangguan adalah peristiwa yang menyebabkan trip-nya PMT diluar kehendak operator (fault). Gangguan umumnya disebabkan karena terjadi hubung singkat. Hubung singkat ini dapat terjadi antara fasa dengan fasa, atau fasa dengan tanah. [2] Macam-macam gangguan dapat dikelompok menjadi :

a. Gangguan Temporer, yaitu peristiwa yang menyebabkan trip-nya PMT tetapi beberapa saat kemudian (setelah 5 detik) apabila PMT dimasukkan, keadaan akan normal kembali (gangguan sudah hilang).

b. Gangguan Permanen, yaitu peristiwa yang menyebabkan trip-nya PMT, kemudian bila PMT dimasukkan kembali, PMT tersebut trip lagi, PMT ini baru bisa dimasukkan kembali secara normal setelah dilakukan perbaikan atas bagian yang menimbulkan gangguan.

Berikut ini adalah gangguan-gangguan yang sering terjadi pada generator : [2]

a. Gangguan Listrik (Electrical Fault) Gangguan listrik adalah ganggu yang timbul dan terjadi pada bagian-bagian listrik dari generator. Gangguan tersebut antara lain :

1) Hubung Singkat Tiga Fasa (Three Phasa Fault)

2) Hubung Singkat Dua Fasa (Two Phase Fault)

3) Stator Hubung Singkat Satu Fasa ke Tanah (Stator Ground Fault)

4) Rotor Hubung Tanah (Field Ground)

5) Kehilangan Medan Penguat (Loss of Excitattion)

6) Tegangan Lebih (Over Voltage)

b. Gangguan Mekanis / Panas (Mechanical Thermal Fault)

1) Generator berfungsi sebagai motor

2) Pemanasan lebih setempat

3) Kesalahan paralel.

4) Gangguan pendingin stator

5) Putaran lebih

c. Gangguan Sistem (System Fault)

Gangguan dapat terganggu akibat adanya gangguan yang datang atau terjadi pada sistem. Gangguan-gangguan sistem yang umumnya terjadi antara lain : 
1) Frekuensi operasi yang tidak normal (abnormal frequency operation)

2) Lepas sinkron (Loss of synchron)

3) Pengaman cadangan (Back up protection)

4) Arus beban kumparan yang tidak seimbang (Unbalanced Armature Current)

Bila suatu mesin listrik secara cepat dilepas setelah terjadinya gangguan pada belitan, maka hanya sebagian kumparan yang perlu diperbaiki. Tetapi, apabila gangguan terjadi secara terus menerus, maka kemungkinan keseluruhan belitan akan rusak dan memerlukan perbaikan total.

\section{Sistem Proteksi}

Dalam melaksanakan pembangkitan, gangguan tidak dapat dihindari sehingga diperlukan sistem proteksi untuk mengamankan generator untuk mencegah terjadinya kerusakan yang lebih besar. Sistem proteksi pada generator harus bekerja dengan cepat ketika terjadi gangguan agar tidak terjadi kerusakan yang meluas pada daerah yang terganggu. [3][4]

Pada sistem proteksi, dikenal 4 komponen utama, yaitu Pemutus Tenaga (PMT), Transformator Instrumen, Baterai, Rele Proteksi dan Pengawatan. Adapun skema sistem proteksi dapat dilihat pada gambar 1 .

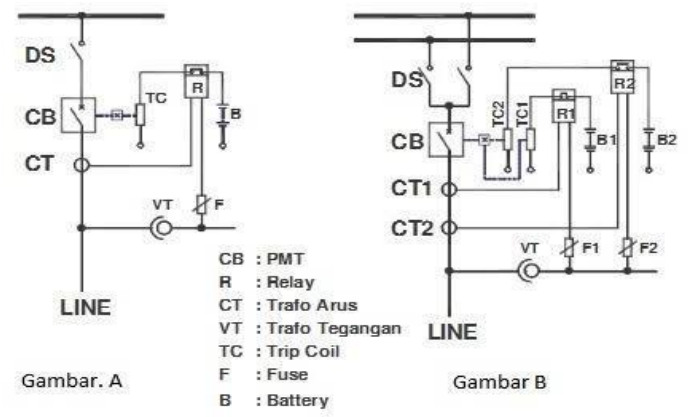

Gambar 1 Skema Sistem Proteksi

Dalam sistem proteksi dikenal istilah zone protection atau wilayah proteksi. Adanya zone protection mengakibatkan sistem proteksi hanya akan mengamankan gangguan yang terjadi di daerah jangkauan proteksinya saja. Hal ini bertujuan untuk mencegah terjadinya pemadaman yang tidak diperlukan pada daerah yang tidak mengalami gangguan. Adapun skema zona proteksi dapat dilihat pada gambar 2.

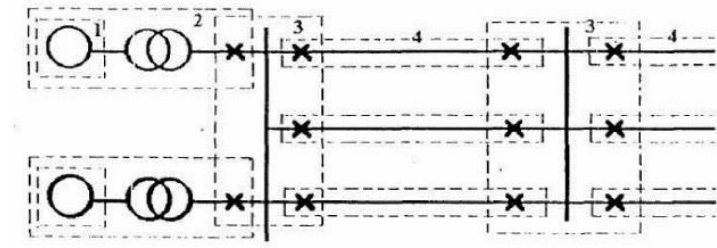

Gambar 2 Skema Zona Proteksi

Keterangan gambar :

Batas zona proteksi ditentukan oleh lokasi CT x Pemutus Tenaga

$$
\begin{array}{ll}
1 & \text { : Zona Proteksi Generator } \\
2 & \text { : Zona Proteksi Generator Unit } \\
3 & : \text { Zona Proteksi Busbar } \\
4 & \text { : Zona Proteksi jaringan transmisi }
\end{array}
$$

Setiap zona mempunyai pola proteksi tertentu dan setiap pola mempunyai sistem proteksi tertentu, dengan proteksi berlapis. Oleh karena itu ada proteksi utama dan proteksi cadangan. Metode proteksi dapat diklasifikasikan sebasgai berikut :

1. Back Up Relay

2. Breaker Back Up Relay

3. Remote Back Up Relay

4. Back Up Relay yang dikoordinasikan secara terpusat

5. Duplicate Relay

Apabila terjadi gangguan, rele akan menjadi elemen perasa untuk mendeteksi gangguan tersebut serta menentukan terjadinya lokasi gangguan. Gangguan yang dideteksi oleh rele akan memicu bekerjanya rangkaian trip dan mengakibatkan pemutus tenaga terbuka untuk memutus gangguan. Dimana rangkaian trip dari rele tidak boleh mengalami kegagalan apabila sewaktu-waktu dilakukan perintah trip, khususnya apabila terjadi gangguan.

Rele proteksi adalah suatu perangkat kerja proteksi yang mempunyai fungsi dan peranan sebagai berikut :

a) Memberikan sinyal alarm atau meleps pemutus tenaga (circuit breaker) dengan tujuan mengisolir gangguan atau kondisi yang abnormal seperti adanya beban lebih, tegangan rendah, kenaikan suhu, beban tidak seimbang, daya kembali, frekuensi rendah, hubungan singkat dan kondisi tidak normal lainnya.

b) Melepas/Mentrip peralatan yang berfungsi tidak normal untuk mencegah timbunya kerusakan. 
c) Melepas/Mentrip peralatan yang terganggu dengan tujuan mengurangi kerusakan yang lebih berat.

d) Melokalisir kemungkinan dampak akibat gangguan dengan memisahkan peralatan yang terganggu dari sistem.

e) Melepas peralatan/ bagian yang terganggu secara cepat dengan maksud menjaga stabilitas, kontiuitas pelayanan dan untuk kerja sistem.

Sebagaimana prinsip kerja sebuah sistem proteksi, rele memiliki peran yang aman penting dalam sebuah sistem proteksi. Agar dapat beroperasi secara optimal, rele proteksi harus memenuhi kriteria-kriteria sebagai berikut :

a) Kepekaan (Sensitivity)

b) Keandalan (Reliability)

1. Dependability

2. Security

c) Selektivitas (Selectivity)

d) Kecepatan (Speed)

Rele proteksi membutuhkan reaksi yang cepat untuk melakukan tindakan pengisoliran disebabkan oleh alasan berikut ini :

1. Waktu pemutusan kritis tidak boleh dilewati

2. Peralatan listrik akan dapat rusak jika arus gangguan dibiarkan terlalu lama

Gangguan yang menetap akan menurunkan tegangan dan dapat memperlambat serta pembebanan lebih pada peralatan penggerak industri.

\section{METODE PENELITIAN}

Penelitian ini dilaksanakan di PT. PLN Sulselrabar PLTD Tello, Makassar. Adapun tahapan-tahapan penelitiannya yaitu mensurvei lapangan untuk medapatkan data-data yang terbaik, mengambil data spesifikasi generator SWD, mengambil data spesifikasi system proteksi untuk generator SWD secara umum, mengambil data spesifikasi generator MITSUBISHI, mengambil data spesifikasi system proteksi untuk generator MITSUBISHI secara umum, mengambil data gangguan yang terjadi pada generator SWD, mengambil data gangguan yang terjadi pada generator MITSUBISHI, dan menganalisis perbandingan yang ada pada sistem proteksi generator SWD dengan generator Mitsubishi di Unit PLTD Tello. Metode yang digunakan dalam penelitian ini yaitu :

\section{Metode Observasi}

Metode observasi adalah metode pengumpulan data yang dilakukan dengan cara melakukan pengamatan langsung di lapangan mengenai permasalahan yang ditinjau. Data-data diambil di ruang kontrol berupa data gangguan yang sering terjadi, spesifikasi generator SWD dan Mitshubishi, dan data lainnya yang diperlukan dan terkait dengan penelitian yang sedang dilakukan.

\section{Metode Literatur}

Metode literatur adalah metode pengumpulan data yang dilakukan dengan cara mengambil data-data yang diperlukan dari literatur-literatur yang berkaitan seperti buku, jurnal, makalah, dan laporan penelitian lainnya yang serupa.

Data yang diperoleh akan diolah dan dianalisis. Adapun nilai yang didapatkan selama penelitian akan diolah secara matematis sesuai standar yang diperoleh dari rekomendasi sistem proteksi yang dikeluarkan oleh PT. PLN (Persero) PLTD Tello dan berlaku untuk waktu tersebut.

\section{HASIL DAN PEMBAHASAN}

Pembangkit Listrik Tenaga Diesel (PLTD) mulai beroperasi secara komersial pada tahun 1973 menggunakan 1 unit generator Mitshubishi dengan kapasitas 12,60 MW, pada tahun 1984, PLTD sudah memiliki 2 unit generator Mitshubishi dengan kapasitas 2x12,60 MW, di tahun 1984 dan 1989, PLTD kembali pengadaan generator dengan jenis yang berbeda, yakni Generator Mitshubishi dengan kapasitas 2x12,40 MW. pada generator SWD dan Mitsubishi menggunakan sistem eksetasi tanpa sikat (Brushless Excitation), hal ini dikarenakan slip ring untuk menyalurkan arus eksitasi ke rotor generator mempunyai kelemahan karena besarnya arus yang mampu dialirkan pada sikat arang relatif lebih kacil. Untuk mengatasi keterbatasan sikat arang, maka generator Mitsubishi menggunakan sistem eksitasi tanpa sikat (Brushless Excitation). Spesifikasi generator dapat dilihat pada tabel 1.

\begin{tabular}{ccc}
\hline \multirow{2}{*}{ SPESIFIKASI } & \multicolumn{2}{c}{ JENIS } \\
& SWD & MITSHUBISHI \\
\hline \multirow{3}{*}{ Pabrik } & Meidensa & \\
& electric & Cademesa \\
& MFG & (Spain) \\
& LTD & \\
\hline Putaran & $428 \mathrm{rpm}$ & $428 \mathrm{rpm}$ \\
\hline
\end{tabular}




\begin{tabular}{ccc}
\hline SPESIFIKASI & \multicolumn{2}{c}{ JENIS } \\
& SWD & MITSHUBISHI \\
\hline Daya Keluaran & $\begin{array}{c}15.750 \\
\mathrm{kVA}\end{array}$ & $15.495 \mathrm{Kva}$ \\
\hline Frekuensi & $50 \mathrm{~Hz}$ & $50 \mathrm{~Hz}$ \\
\hline Tegangan & $6300 \mathrm{Volt}$ & $6300 \mathrm{Volt}$ \\
\hline Arus Keluaran & $\begin{array}{c}1443 \\
\text { Ampere }\end{array}$ & $1443 \mathrm{Amper}$ \\
\hline Phasa & 3 & 3 \\
\hline Faktor Daya & $\begin{array}{c}0.8 \\
(\text { Lagging) }\end{array}$ & $0.8($ Lagging) \\
\hline Type & $\begin{array}{c}\text { WA } \\
242 / 87 / 14\end{array}$ & WA $242 / 87 / 14$ \\
\hline Hubungan & Bintang & Bintang \\
\hline Stator & $\mathrm{F}$ & $\mathrm{F}$ \\
\hline Jenis Isolasi & $520 \Omega$, & $520 \Omega, 7 \mathrm{~A} / 5 \mathrm{~min}$ \\
\hline NGR & $7 \mathrm{~A} / 5 \mathrm{~min}$
\end{tabular}

Relay proteksi yang terdapat pada generator SWD PLTD Tello PT.PLN (Persero) berjumlah 7 relay proteksi, diantaranya :

i. Over Current Relay

ii. Reverse Power relay

iii. Generator Differential relay

iv. Under dan Over Voltage Relay

v. Stator Earth fault Relay

vi. Rotor Earth fault Relay

vii. Ocr. Neutral dan Ground Fault Transformator Utama $150 \mathrm{KV}$

Relay proteksi yang terdapat pada generator Mitsubishi PLTD Tello PT. PLN (Persero) berjumlah 12 relay proteksi :
i. Over Current Relay
ii. Generator Differential Relay
iii. Reverse Power Relay
iv. Over Voltage Relay
v. Ground Fault Relay
vi. Loss Of Field Relay
vii. Over Voltage Ground Relay (264B1)
viii. Over Voltage Ground Relay (264B2)
ix. Ground Over Current Relay Transformator Utama $150 \mathrm{KV}$
x. Static Differential Relay Transformator Utama 150 KV (87MT1 Phase R)
xi. Static Differential Relay Transformator Utama 150 KV (87MT1 Phase S)
xii. Static Differential Relay Transformator Utama 150 KV (87MT1 Phase T).

Pada tanggal 4 Januari 2015 terjadi gangguan pada generator pada generator jenis Mitshubishi yang disebabkan karena adanya kesalahan pemasangan pada transformator arus sehingga differensial relay bekerja, adapun material yang dirusak adalah isolasi belitan pada generator meleleh, tindakan oleh pihak PLTD Sektor Tello adalah mengecek dan memperbaiki isolasi pada belitan serta memperbaiki pemasangan pada transformator arus.

Pada tanggal 10 Maret 2016 gangguan juga terjadi pada generator SWD yang disebabkan karena adanya kekeliruan pada saat penyettingan timer distribusi ke AVR yang waktunya agak lama sehingga tegangan naik dan menimbulkan Overvoltage, tindakan oleh pihak PLTD Sektor Tello adalah menyetting kembali timer sehingga tegangan kembali normal.

\section{KESIMPULAN}

1. Relay proteksi generator SWD PLTD Tello PT.PLN (Persero) terdiri dari 7 proteksi.Sedangkan pada Relay proteksi generator Mitsubishi PLTD Tello PT. PLN (Persero) terdiri dari 12 proteksi.

2. Gangguan yang terjadi pada rentang tahun 2015 sampai 2016, pada generator jenis Mitshubishi yaitu Penyettingan timer distribusi ke AVR yang delaynya agak lama sehingga tegangan naik dan menimbulkan Overvoltage sedangkan pada generator jenis SWD Kesalahan pemasangan pada transformator arus sehingga differensial relay bekerja.

3. Gangguan pada generator minim dikarenakan, generator SWD dan generator Mitsubishi jarang beroperasi.

\section{UCAPAN TERIMA KASIH}

Ucapan terima kasih ditujukan kepada :

1. Syahrul Amirullah Burhan yang telah membantu dalam dalam pengambilan data penelitian ini .

2. Ahmad Rizal Sultan, S.T., M.T. atas masukan perbaikan terhadap penelitian ini 


\section{REFERENSI}

[1] Onny. 2016. Macam-macam Generator AC. www. Artikelteknologi.com/macam-macam- generatorac/3/.

[2] Sumanto. 1999. Mesin Sinkron.Jakarta : Andi Offset.

[3] Tandiaji, Sony, Thaha, Sarma. Sistem Proteksi Tenaga Listrik.2015.

[4] Kurniawati N, Naelly M, Nurismawati, Irvan S,2017, Rekonfigurasi Jtr Akibat Tingginya Rugi Daya Dan Jatuh Tegangan Pada Area Btn Hamzy Dan Btn Antara,jurnal teknologi elekterika Vol 14, No 2 ,Halaman 105-125. 